\title{
Formulation and evaluation of monolithic matrix polymer films for transdermal delivery of nitrendipine
}

\author{
ASHU MITTAL ${ }^{* 1}$ \\ UDAI VIR SINGH SARA ${ }^{2}$ \\ ASGAR ALI ${ }^{3}$ \\ ${ }^{1}$ ITS-Paramedical (Pharmacy) \\ College, Ghaziabad, India \\ ${ }^{2}$ D. J. College of Pharmacy \\ Ghaziabad, India \\ ${ }^{3}$ Deparment of Pharmaceutics \\ Faculty of Pharmacy, Hamdard \\ University, New Delhi, India
}

Accepted July 27, 2009

\begin{abstract}
The objective of the present work was to develop a suitable transdermal drug delivery system for nitrendipine. Polymeric films of nitrendipine were prepared by the film casting technique (glass ring) on mercury substrate. They were evaluated for physicochemical parameters, in vitro release and ex vivo permeation (heat separated human epidermis). Release of the drug from the films followed anomalous transport $(0.5<n<1)$.

Polymeric combination containing Eudragit RL 100:PVP $\mathrm{K} 30$ in a 4:6 ratio showed the best results. Maximum drug release and skin permeability coefficient in $48 \mathrm{~h}$ were $85.8 \%$ and $0.0142 \mathrm{~cm} \mathrm{~h}^{-1}$, respectively, in formulation C3 (Eudragit RL 100/Plasdone S 630; 4:6) and $88.0 \%$ and $0.0155 \mathrm{~cm} \mathrm{~h}^{-1}$, respectively, in formulation, D3 (Eudragit RL 100/PVP K 30; 4:6). FTIR and TLC studies indicated no drug and polymer interaction.
\end{abstract}

Keywords: nitrendipine, polymeric film, transdermal drug delivery, Eudragit RL 100, Plasdone S 630, PVP K 30

Transdermal delivery has many advantages over conventional modes of drug administration; especially, it avoids hepatic first pass metabolism and improves patient compliance (1). Intensive research has shown that the transdermal route is a potential mode of delivery of lipophilic drugs in the systemic circulation (2). Nitrendipine (NTP) was used as the model drug. Nitrendipine is a lipophilic drug used for the management of mild to moderate essential hypertension. It possesses low oral bioavailability ( $20 \%$ ) due to hepatic first pass metabolism after oral administration (3). Hence, NTP is an ideal drug candidate for transdermal drug delivery. In the present study, polymeric films containing nitrendipine as a model drug and oleic acid as a penetration enhancer (4) were prepared using a novel combination of Eudragit RL 100 and Plasdone S 630 (polyvinyl pyrollidone vinyl acetate, copovidne)/PVP K 30 (polyvinyl pyrollidone, povidone) for transdermal application and were evaluated for their physicochemical characteristics as well as for their in vitro drug release and skin permeation potential.

\footnotetext{
* Correspondence; e-mail: mittalashu@yahoo.com
} 


\section{EXPERIMENTAL}

\section{Materials}

Niterendipine was provided by courtesy of Concept Pharmaceuticals, India. Plasdone S 630 was donated by Jubliant Organosys, India. Eudragit RL 100 (ERL 100) was received as a gift sample from Degussa, India. PVP K 30 was purchased from SD Fine Chemicals Ltd, India. Dibutyl phthalate (DBP) and oleic acid were purchased from CDH, India. HPLC grade solvents were purchased from Rankem, India. Other materials used in the study were of analytical grade. Doubly distilled water was used throughout the study.

\section{Dose design}

The dose to be incorporated in a patch was calculated using the following mathematical equation (1):

$$
\text { drug input (theoretical) }=\mathrm{C}_{\mathrm{ss}} \times k_{\mathrm{e}} \times V_{\mathrm{d}}
$$

giving: $25 \mu \mathrm{g} \mathrm{L}-1 \times 0.057 \mathrm{~h}^{-1} \times 350 \mathrm{~L}=498.75 \mu \mathrm{g} \mathrm{h} \mathrm{r}^{-1}$

where $C_{\mathrm{ss}}$ is concentration at steady state, $k_{\mathrm{e}}$ is elimination rate constant and $V_{\mathrm{d}}$ is volume of distribution.

Dose required for a patch $=$ drug input $\times$ delivery time

giving: $498.75 \mu \mathrm{g} \mathrm{h}^{-1} \times 48 \mathrm{~h}=24 \mathrm{mg}$ per patch

\section{Development of polymeric films}

Polymeric films were prepared by the film casting technique on mercury substrate (15). Series of C and D formulations were prepared using different ratios of polymers (Table I), along with $16.66 \%(\mathrm{~m} / \mathrm{m})$ of nitrendipine, $10 \%(\mathrm{~m} / \mathrm{m})$ of plasticizer (dibutylphthalate), and $5 \%(\mathrm{~m} / \mathrm{m})$ of penetration enhancer, oleic acid (based on total polymer mass) in a mixture of dichloromethane and methanol (50:50, $V / V)$. The resulting solution was poured into a glass ring of $6.00 \mathrm{~cm}$ (internal diameter) and placed into mercury in a Petri dish. The solvent was allowed to evaporate under ambient conditions (temperature $32 \pm 2{ }^{\circ} \mathrm{C}$, RH $45 \pm 5 \%$ ) for 24 hours. The dried films of $6.74 \mathrm{~cm}^{2}$ were then cut with a circular metallic die of $2.93 \mathrm{~cm}$ (internal diameter). The films were stored between sheets of wax paper in a desiccator.

\section{Solubility studies}

Solubility studies were carried out by adding an excess amount of drug in 20:80 isopopyl alcohol to phosphate buffer ( $\mathrm{pH} \mathrm{7.4)}$ and keeping the flasks containing the solutions on a mechanical shaker for $24 \mathrm{~h}$ at $25^{\circ} \mathrm{C}$. After $24 \mathrm{~h}$, the solution was transferred 
into test tubes and centrifuged at $2000 \mathrm{rpm}$ for $30 \mathrm{~min}$ at room temperature. The test tubes were placed aside to settle for $30 \mathrm{~min}$. From each test tube, $1 \mathrm{~mL}$ of supernatant was placed into a 100-mL volumetric flask and diluted with blank solution. The mixture was filtered and absorbance was read at $355 \mathrm{~nm}$ with a double beam UV-Vis spectrophotometer (Systronics PC based double beam spectrophotometer, 2202, Systronics, India). The amount of drug dissolved was quantified from the standard curve $\left(R^{2}=0.9999\right)$.

\section{Interaction studies}

Interaction studies were conducted on the optimized formulation (D-3) by comparing at with pure drug, polymers and mixture of drug and polymers on the basis of FTIR (Jasco 4100, Japan) and TLC (6). IR absorption spectra were taken in the range of 400-4000 $\mathrm{cm}^{-1}$ using the potassium bromide disc method. TLC studies were performed on $0.25-\mathrm{mm}$ silica gel G plates using ethyl acetate/chloroform (1:9) as developer and iodine vapors as visualizing agent.

\section{Evaluation of polymeric films}

The films were evaluated for physical appearance, moisture content, thickness, flatness, folding endurance, tensile strength (percentage elongation at break), drug content and mass $(6,7)$.

\section{In vitro dissolution studies}

A modified paddle over disc assembly was used for assessment of drug release from the films. The film was mounted on the disc and placed at the bottom of the dissolution vessel. The dissolution medium was $900 \mathrm{~mL}$ solution of isopropyl alcohol and isotonic phosphate buffer of $\mathrm{pH} 7.4$ in the ratio of 20:80. The apparatus was equilibrated to $32 \pm$ $0.5{ }^{\circ} \mathrm{C}$ and operated at $50 \mathrm{rpm}$. The samples (3-mL aliquots) were withdrawn at appropriate time intervals up to $48 \mathrm{~h}$, filtered, and analyzed at $355 \mathrm{~nm}$. After each sampling, an equal volume of drug-free solution of isopropyl alcohol and isotonic phosphate buffer of $\mathrm{pH}$ 7.4, 20:80, was added to the dissolution medium to maintain a constant volume. Necessary corrections were made to the calculations for the loss of drug due to each sampling. The experiment was done in triplicate and the mean value was calculated.

\section{Release mechanism}

Drug release mechanism was analyzed using the Zero-Order Model, First-Order Model, Higuchi Model and Korsmeyer-Peppas Model (8).

\section{In vitro permeation studies}

The study was approved by the Ethics Committee of ITS-Paramedical (Pharmacy) College Ghaziabad, India. A fabricated diffusion cell with a diffusional area of $6.74 \mathrm{~cm}^{2}$ was used. Ex vivo skin permeation studies were performed on heat separated human epidermis. Human cadaver skin (abdominal area) was acquired from the Department of Anatomy, ITS-Centre for Dental Studies and Research, Muradnagar, India. The subcuta- 
neous fatty tissue was removed with surgical scissors. For permeation experiments, heat separated human epidermis was prepared (9). The skin was immersed into warm water at $60^{\circ} \mathrm{C}$ for $2 \mathrm{~min}$, the whole epidermal layer was carefully separated from the dermis using blunt forceps. The obtained epidermis was wrapped in aluminum foil and stored at $-20{ }^{\circ} \mathrm{C}$ until use. Before the experiment, the skin was taken out and thawed until it reached room temperature. It was gently blotted dry with filter paper. The integrity of the skin was tested microscopically before use in the diffusion cell (10). The stratum corneum side of the skin was kept in intimate contact with the release surface of the polymeric film (kept in the donor cell). The receiver phase was a 50-mL mixture of isopropyl alcohol and IPB of pH 7.4 in the ratio of 20:80 stirred at $500 \mathrm{rpm}$ on a magnetic stirrer (11). The contents of the receiver cell were kept at $32 \pm 0.5{ }^{\circ} \mathrm{C}$ with prewarmed water flowing through a jacket lined with the receiver cell. The amount of drug permeated was determined by removing 1-mL samples at appropriate time intervals up to $48 \mathrm{~h}$ followed by UV analysis. The volume was replenished with an equal quantity of prewarmed receiver solution. The amount of drug permeated per square centimeter at each time interval was calculated from the calibration curve.

\section{Determination of permeation parameters}

Permeation profiles of nitrendipine were constructed by plotting the cumulative amount of the drug permeated per unit area as a function of time. The graph showed an initial lag time followed by, the linear phase, which was consistent with the steady-state Fickian diffusion. The flux was calculated from the slope. In all experiments, the same number of data points was taken to calculate the flux $(J)$; the permeability coefficient $\left(P_{c}\right)$ was calculated by dividing the flux by the initial drug load $(C)(12)$ :

$$
P_{c}=J / C
$$

\section{Statistical analysis}

GraphPadIn Stat Version 3.0 Software was used for statistical analysis. The results were expressed as arithmetic mean $\pm \mathrm{SD}$. The statistical analysis was performed using Student's $t$-test and ANOVA. Kolmogorov Smirnov distance (KS) test was performed to test whether two samples were drawn from identical distributions.

\section{RESULTS AND DISCUSSION}

\section{Solubility study}

An attempt was made at this point to learn whether the medium 20:80 isopropanol/phosphate buffer $\mathrm{pH} 7.4$ was able to maintain skin conditions in dissolution studies as well as in permeation studies. The concentration of the drug dissolved (solubility) in the medium was $2.42 \mathrm{mg} \mathrm{mL}^{-1}$, which is 90.8 times higher than the required solubility $\left(0.026 \mathrm{mg} \mathrm{mL}^{-1}\right)$ in case of dissolution studies and 5.0 times higher than the required solubility $\left(0.48 \mathrm{mg} \mathrm{mL}^{-1}\right)$ in case of permeation studies. Results showed that the above 
medium could be chosen as the dissolution and permeation medium because a sufficient amount of drug, necessary to maintain the sink conditions, dissolves in it. Further, the above medium does not affect the barrier function of the epidermis as lower alcohol concentration does not extract the lipid fraction from the stratum corneum $(13,14)$.
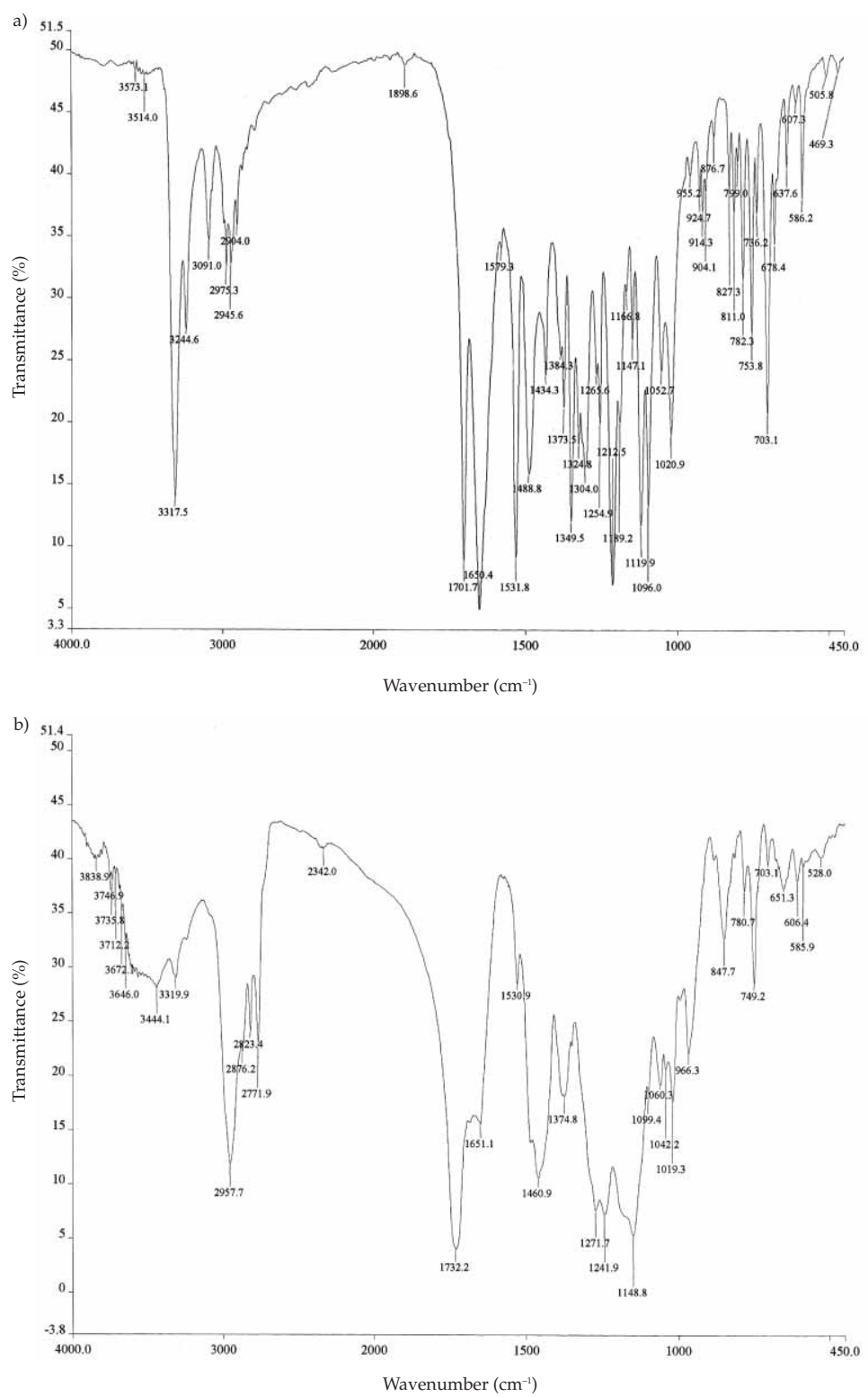

Fig. 1. IR spectra of: a) nitrendipine, b) physical mixture of nitrendipine and polymers. 


\section{Interaction studies}

The $R_{\mathrm{f}}$ values for the pure drug and the mixture were 0.66 and 0.68 , respectively. The IR spectral analysis of nitrendipine alone (Fig. 1a) showed that principal peaks were observed at wave numbers of 1701.7 (esterified carbonyl group), 1650.4 (N-H bending vibration for secondary amines), 1531.8 (aryl nitro group), $1096.0 \mathrm{~cm}^{-1}$ (CN vibrations) and the same peaks at 1701.7, 1651.1, 1530.9, $1099.4 \mathrm{~cm}^{-1}$ were observed in the spectra of the optimized medicated film (Fig. 1b). Some additional peaks were aso observed in physical mixtures, which could be due to the presence of polymers. As principal peaks of IR spectra of pure drug appeared in the IR spectra of medicated film, it can be concluded that there was no chemical interaction between the drug and the polymers. Further TLC results support the data obtained from IR spectra that there was no interaction between the drug and the polymers used in the study.

\section{Evaluation of polymeric films}

On the basis of visual characterization, films C1, C2, D1 and D2 were rejected as they were moderately sticky and wrinkled and it would be difficult to handle such films and they could not be subjected to any kind of evaluation. The data of the selected films are presented in Table I and II. The drug content analysis of the prepared films showed that the process used to prepare the films is capable of giving uniform drug content (99.5-99.9 \% trought both series C and D) and minimum batch variability (Table II). The results reveal that the films have reasonable flexibility and moderate percentage elongation. The folding endurance in series C and D is ranges from 92 to $135 \%$ and elongation at break from 14 to $37 \%$. The folding endurance decreased with increasing concentration of PVP/Plasdone S 630. In spite of variations in this physical parameter, all films were found to be smooth and flexible, which might be attributed to addition of the plasticizer dibutyl phthalate $(10 \%, m / m$, of polymer mass). No constriction was observed in any of the prepared films, which indicates smooth flat surface of the films.

Table I. Composition and visual characterization of nitrendipine polymeric films

\begin{tabular}{|c|c|c|}
\hline Code & Polymers (ratio) & Visual characterization \\
\hline C3 & ERL 100/Plasdone S 630 (4:6) & smooth, uniform and flexible \\
\hline $\mathrm{C} 4$ & ERL 100/Plasdone S 630 (5:5) & smooth, uniform and flexible \\
\hline C5 & ERL 100/Plasdone S $630(6: 4)$ & smooth, uniform and flexible \\
\hline C6 & ERL 100/Plasdone S 630 (7:3) & smooth, uniform and flexible \\
\hline $\mathrm{C} 7$ & ERL 100/Plasdone S 630 (8:2) & smooth, uniform and flexible \\
\hline D3 & ERL 100/PVP K30 (4:6) & $\begin{array}{l}\text { slightly sticky, smooth, uniform } \\
\text { and slightly tough }\end{array}$ \\
\hline D4 & ERL 100/PVP K30 (5:5) & smooth, uniform and flexible \\
\hline D5 & ERL 100/PVP K30 (6:4) & smooth, uniform and flexible \\
\hline D6 & ERL 100/PVP K30 (7:3) & smooth, uniform and flexible \\
\hline D7 & ERL 100/PVP K30 (8:2) & smooth, uniform and flexible \\
\hline
\end{tabular}


A. Mittal et al.: Formulation and evaluation of monolithic matrix polymer films for transdermal delivery of nitrendipine, Acta Pharm. 59 (2009) 383-393.

Table II. Physical characterization of nitrendipine films

\begin{tabular}{ccccccc}
\hline Code & $\begin{array}{c}\text { Thickness } \\
(\mathrm{mm})^{\mathrm{a}}\end{array}$ & $\begin{array}{c}\text { Moisture } \\
\text { content }(\%)^{\mathrm{a}}\end{array}$ & $\begin{array}{c}\text { Folding } \\
\text { endurance }(\%)^{\mathrm{a}}\end{array}$ & $\begin{array}{c}\text { Elongation at } \\
\text { break }(\%)^{\mathrm{a}}\end{array}$ & $\begin{array}{c}\text { Mass }^{\mathrm{a}} \\
(\mathrm{mg})\end{array}$ & $\begin{array}{c}\text { Drug } \\
\text { content }(\%)^{\mathrm{a}}\end{array}$ \\
\hline C3 & $0.391 \pm 0.015$ & $3.05 \pm 0.46$ & $105 \pm 5.7$ & $19 \pm 3.633$ & $198.20 \pm 1.3$ & $99.62 \pm 0.214$ \\
C4 & $0.382 \pm 0.022$ & $2.87 \pm 0.37$ & $115 \pm 12.9$ & $25 \pm 2.898$ & $198.35 \pm 1.2$ & $99.65 \pm 0.204$ \\
C5 & $0.392 \pm 0.024$ & $2.66 \pm 0.29$ & $122 \pm 17.0$ & $29 \pm 4.195$ & $197.55 \pm 2.2$ & $99.66 \pm 0.217$ \\
C6 & $0.393 \pm 0.023$ & $2.54 \pm 0.33$ & $127 \pm 12.5$ & $33 \pm 3.033$ & $197.74 \pm 1.3$ & $99.64 \pm 0.230$ \\
C7 & $0.393 \pm 0.024$ & $2.28 \pm 0.40$ & $135 \pm 12.9$ & $37 \pm 5.692$ & $197.85 \pm 1.7$ & $99.72 \pm 0.192$ \\
D3 & $0.395 \pm 0.016$ & $4.03 \pm 0.17$ & $92 \pm 9.5$ & $14 \pm 4.336$ & $198.95 \pm 0.96$ & $99.91 \pm 0.153$ \\
D4 & $0.396 \pm 0.018$ & $3.17 \pm 0.12$ & $102 \pm 9.5$ & $18 \pm 2.608$ & $198.92 \pm 0.79$ & $99.65 \pm 0.197$ \\
D5 & $0.397 \pm 0.017$ & $2.91 \pm 0.17$ & $110 \pm 8.1$ & $21 \pm 3.633$ & $198.45 \pm 0.79$ & $99.54 \pm 0.161$ \\
D6 & $0.399 \pm 0.018$ & $2.48 \pm 0.13$ & $115 \pm 12.9$ & $24 \pm 3.347$ & $198.37 \pm 1.18$ & $99.65 \pm 0.176$ \\
D7 & $0.401 \pm 0.022$ & $2.25 \pm 0.12$ & $122 \pm 12.5$ & $31 \pm 3.633$ & $198.47 \pm 1.01$ & $99.57 \pm 0.221$ \\
\hline
\end{tabular}

a Mean $\pm \mathrm{SD}, n=3$.

\section{In vitro dissolution studies}

In this study, the effect of various polymeric combinations on the release behaviour and kinetics of NTP from transdermal films was evaluated. In order to describe the kinetics of drug release from transdermal films, various mathematical models were used (8). The data is presented in Table III. The release of drug from all the films followed anomalous transport $(0.5<n<1)$; however, films containing higher concentration of copovidone/povidone (C3 and D3) showed higher release and exhibited release order towards the first-order (pseudo first-order) and Fickian diffusion as release mechanism $(n \approx 0.5)$. Films containing higher content of Eudragit RL 100 showed lesser release and exhibited release mechanism towards case II transport. The reason for films C3 and D3 to exhibit pseudo Fickian first-order diffusion may be the leaching of PVP/Plasdone S 630 and pore formation. This led to an increase in the external film area exposed to the solvent, increased internal porosity and decreased tortuosity. With an increase in porosity, the void volume would be expected to be occupied by external solvent diffusing into the film (15). In case of films C7 and D7, containing a higher content of the rate controlling polymer (Eudragit RL 100), lesser release and case II transport release mechanism might be due to the increase in the time needed to release a given quantity of drug, allowing higher hydration and relaxation of the polymer matrix before release. The release profiles of the films are shown in Figs. 2a and b. Maximum percentage of drug released $(88.0 \%)$ was found for formulation D3 (PVP/E PO, 6:4) and minimum percentage of drug released (68.8\%) was observed for film D7 (PVP/E PO, 2:8) in series D formulations. Similar observations were observed in series $C$ films, $C 3$ showed maximum release of $85.8 \%$, whereas C7 showed minimum drug release of $60.6 \%$. Film D3 (containing PVP K 30 polymer) showed higher release than C3 (containing Plasdone S 630). (Student's $t$-test, $p=0.0005, \mathrm{KS}=0.18$ ). Significant differences in drug release were absowed between films of series $C$ and D (ANOVA, $p<0.05$ ). This might be due to the 

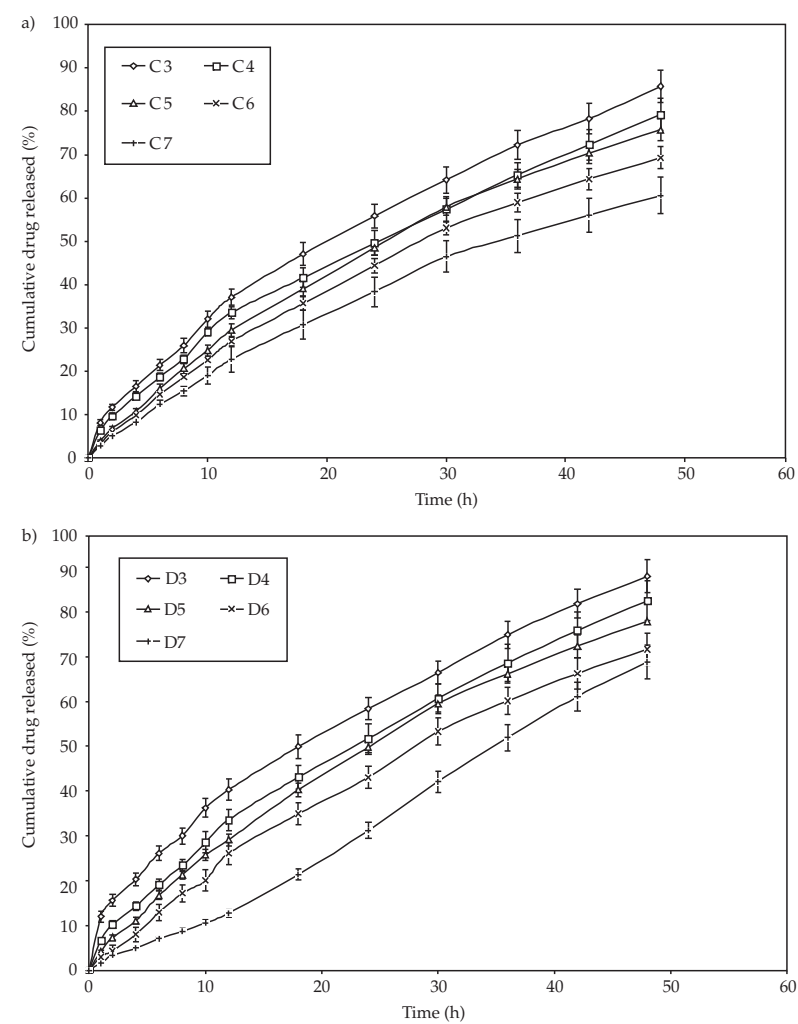

Fig. 2. In vitro drug release profile of nitrendipine (modified paddle dissolution apparatus in 20:80 isopropyl alcohol/phosphate buffer $\mathrm{pH}$ 7.4) from drug matrix patches: a) Eudragit RL/Plasdone $\mathrm{S}$ 630 (series C), b) Eudragit RL/PVK K 30 (series D) (mean \pm SC, $n=3$ ).

presence of vinyl acetate component in Plasdone S 630 polymer (serias C), which is somewhat more hydrophobic. It appears that water solubility of antinucleating polymers influences the drug release and permeation of the drug from the matrix type transdermal film.

\section{In vitro drug permeation studies}

Drug permeation profiles from series C and D films were more or less rectilinear and were indicative of the steady and slow permeation of the drug in vitro (Table IV). The influence of film composition on permeation parameters is shown in Table IV. Higher NTP flux was observed with higher concentration of PVP K 30/Plasdone S 630 concentration in films (Table IV). Improvement in skin flux with the increase of PVP K 30/Plasdone S-630 content may be due to its antinucleating effect that converts the crystalline drug into an amorphous state, which generally possesses a high energy state with solubility. Enhancement in drug solubility provides increased thermodynamic activity, which facilitates skin permeation of the drug (15). 
A. Mittal et al.: Formulation and evaluation of monolithic matrix polymer films for transdermal delivery of nitrendipine, Acta Pharm. 59 (2009) 383-393.

Table III. Model fitting of the nitrendipine release profile

\begin{tabular}{cccccccc}
\hline \multirow{2}{*}{ Code } & \multicolumn{2}{c}{ Zero-order } & \multicolumn{2}{c}{ First-order } & \multicolumn{2}{c}{ Higuchi } & \multirow{2}{*}{$n$} \\
\cline { 2 - 6 } & $R^{2}$ & $k_{0}\left(\% \mathrm{~h}^{-1}\right)$ & $R^{2}$ & $k_{1}\left(\% \mathrm{~h}^{-1}\right)$ & $R^{2}$ & $k^{\mathrm{H}}\left(\% \mathrm{~h}^{-1 / 2}\right)$ & \\
\hline C3 & 0.978 & 3.38 & 0.987 & 0.0431 & 0.995 & 10.33 & 0.618 \\
C4 & 0.981 & 2.91 & 0.991 & 0.034 & 0.994 & 9.15 & 0.661 \\
C5 & 0.979 & 2.41 & 0.999 & 0.029 & 0.993 & 8.20 & 0.800 \\
C6 & 0.979 & 2.17 & 0.999 & 0.026 & 0.993 & 7.47 & 0.810 \\
C7 & 0.997 & 1.85 & 0.970 & 0.021 & 0.931 & 6.41 & 0.942 \\
D3 & 0.979 & 4.09 & 0.985 & 0.052 & 0.995 & 11.64 & 0.510 \\
D4 & 0.985 & 3.00 & 0.989 & 0.037 & 0.992 & 9.44 & 0.653 \\
D5 & 0.981 & 2.50 & 0.997 & 0.031 & 0.992 & 8.45 & 0.784 \\
D6 & 0.982 & 1.98 & 0.994 & 0.031 & 0.988 & 7.06 & 0.888 \\
D7 & 0.993 & 1.31 & 0.964 & 0.015 & 0.929 & 5.11 & 0.952 \\
\hline
\end{tabular}

$k_{0}$ - zero-order rate constant, $k_{1}$ - first-order rate constant, $k^{\mathrm{H}}-$ Higuchi rate constant, $n$ - Korsmeyer-Peppas release exponent

Table IV. In vitro skin permeation parameters of the polymeric films of nitrendipine

\begin{tabular}{cccc}
\hline & \multicolumn{3}{c}{ In vitro permeation parameter } \\
\cline { 2 - 4 } Code & CADP $(48 \mathrm{~h})(\%)^{\mathrm{a}}$ & Flux $\times 10^{4}\left(\mathrm{mg} \mathrm{cm}^{-2} \mathrm{~h}^{-1}\right)$ & $\mathrm{Pc}\left(\mu \mathrm{m} \mathrm{h}^{-1}\right)$ \\
\hline C3 & $69.2 \pm 1.5$ & 508 & 142 \\
C4 & $63.9 \pm 1.7$ & 471 & 132 \\
C5 & $60.1 \pm 3.5$ & 442 & 124 \\
C6 & $54.9 \pm 1.7$ & 405 & 113 \\
C7 & $50.1 \pm 1.8$ & 371 & 104 \\
D3 & $75.4 \pm 1.9$ & 554 & 155 \\
D4 & $71.5 \pm 1.5$ & 523 & 146 \\
D5 & $63.3 \pm 1.6$ & 467 & 131 \\
D6 & $59.4 \pm 2.1$ & 437 & 122 \\
D7 & $54.1 \pm 1.8$ & 399 & 111 \\
\hline
\end{tabular}

CAPD - Cumulative amount of drug permeated.

Pc - permeability coefficient.

a Mean \pm SEM, $n=3$.

\section{CONCLUSIONS}

The nitrendipine polymeric films containing Plasdone S 630 were found to have higher flexibility compared to those containing PVP K 30. Combination of polymers Eudragit RL 100/PVP K 30 in the ratio of 4:6 showed the best results. In vitro dissolution 
studies revealed that the release of the drug from the films followed anomalous transport $(0.5<n<1)$; however, films containing higher levels of PVP/Plasdone S 630 showed the release mechanism towards Fickian first-order diffusion whereas those containing higher concentration of Eudragit 100 showed pseudo case II transport mechanism. In vitro permeation indicated zero-order kinetics in all the films prepared. The release of the drug was sustained and it extended over a period of $48 \mathrm{~h}$ in all developed films. The IR and TLC studies revealed that there was no interaction between the drug and the polymers used for making matrices. The above data thus support the assimption that these films might be suitable for transdermal application.

Acknowledgements. - We thank Professor Brijendra Singh, ITS-Centre for Dental Studies and Research (CDSR), Ghaziabad, for his help in carrying out this research. Special thanks go to Concept Pharmaceuticals Ltd, Aurangabad, for providing a gift sample of nitrendipine, Jubiliant Organosys, Noida, for providing a gift sample of Plasdone S 630, Degussa India Limited, Mumbai, for providing a gift sample of Eudragit RL 100, ITS-CDSR, Muradnagar (Ghaziabad) for providing human cadaver skin samples. We also thank the Management, ITS-Paramedical (Pharmacy) College, Muradnagar, India, for providing the facilities to carry out this research.

\section{REFERENCES}

1. N. T. Dnyanesh and P. R. Vavia, Acrylate-based transdermal therapeutic system of nitrendipine, Drug Dev. Ind. Pharm. 29 (2003) 71-78; DOI: 10.1081/DDC-1200166851.

2. B. W. Barry, Dermatological Formulation, Marcel Dekker, New York 1983, pp. 225-238.

3. G. R. Aronoff and R. S. Sloan, Nitrendipine kinetics in normal and impaired renal function, Clin. Pharmacol. Ther. 38 (1985) 212-218; DOI: 10.1038/clpt.1985.161.

4. A. Mittal, U. V. S. Sara, A. Asgar and M. Aqil, The effect of penetration enhancers on permeation kinetics of nitrendipine in two different skin models, Biol. Pharm. Bull. 31 (2008) 1766-1772; DOI: $10.1248 / \mathrm{bpb} .31 .1766$.

5. M. Aqil, A. Ali, Y. Sultana and P. Nayyar, Matrix type transdermal drug delivery systems of metoprolol tartrate: skin toxicity and in vivo characterization, Ethiop. Pharm. J. 22 (2004) 53-60.

6. P. Arora and M. Biswajit, Design, development, physicochemical, and in vitro and in vivo evaluation of transdermal patches containg diclofenac diethylammonium salt, J. Pharm. Sci. 91 (2002) 2076-2089; DOI: 10.1002/jps.10200.

7. Udhumansha, M. V. S. Reddy, R. Kumaresan, F. J. Ahmad and R. K. Khar, Transdermal therapeutic system of carvedilol: effect of hydrophilic and hydrophobic matrix on in vitro and in vivo characteristics, AAPS PharmSciTech. 8 (2007) 1-8; DOI: 10.1208/pt0801002.

8. P. Costa and S. J. M. Lobo, Modeling and comparison of dissolution profiles, Eur. J. Pharm. Sci. 13 (2001) 123-133; DOI: 10.1016/s0928-0987(01)00095-1.

9. J. Reichling, U. Landvatter, H. Wagner, H. K. Kostka and F. U. Schaefer, In vitro studies on release and human skin permeation of Australian tea tree oil from topical formulations, Eur. J. Pharm. Biopharm. 64 (2006) 222-228; DOI: 10.1016/j.ejpb.2006.05.006.

10. S. Sonkro, Y. Purwo, G. Becket and T. Rades, Investigation of newborn pig skin as an in vitro animal model for transdermal drug delivery, STP Pharm. Sci. 13 (2003) 133-139.

11. A. P. Kakkar and A. Gupta, Gelatin based transdermal therapeutic system, Indian Drug 29 (1992) 308-312. 
12. H. K. Vaddi, P. C. Ho and S. Y. Chan, Terpenes in propylene glycol as skin penetration enhancers: Permeation and partition of haloperidol, Fourier transform infrared spectroscopy, and differential scanning calorimetry, J. Pharm. Sci. 91 (2002) 1639-1651; DOI: 10.1002/jps.10160.

13. D. Bommannan, R. O. Potts and R. H. Guy, Examination of the effect of ethanol on human stratum corneum in vivo using infrared spectroscopy. J. Control. Rel. 16 (1991) 299-304; DOI: 10.1016/0168-3659(91)90006-Y.

14. O. Yasuko, T. Kozo, M. Yoshie, M. Yoshiharu and T. Nagai, Effect of ethanol on skin permeation of nonionized and ionized diclofenac. Int. J.Pharm. 89 (1993) 191-198; DOI: 10.1016/0378-5173 (93)90243-9.

15. P. R. Roa and P. V. Diwan, Formulation and in vitro evaluation of polymeric films of diltiazem hydrochloride and indomethacin for transdermal administration, Drug Dev. Ind. Pharm. 24 (1998) 327-336; DOI: 10.3109/03639049809085627.

\title{
$S A \check{Z} E T A K$
}

\section{Formulacija i evaluacija monolitnih matriksnih polimernih filmova za transdermalnu isporuku nitrendipina}

\author{
ASHU MITTAL, UDAI VIR SINGH SARA i ASGAR ALI
}

Cilj rada bio je razvoj transdermalnog sustava nitrendipina. Polimerni filmovi nitrendipina pripravljeni su metodom lijevanja (stakleni prsten) na podlozi od žive. Ispitivani su fizičkokemijski parametri, in vitro oslobađanje i ex vivo permeacija (toplinom odvojena humana epiderma). Oslobađanje lijeka iz filmova slijedilo je anomalni transport $(0,5<n<1)$. Najbolji rezultati postignuti su kombinacijom polimera Eudragit RL 100 i PVP K 30 u omjeru 4:6. Maksimalno oslobađanje ljekovite tvari i najbolji koeficijent permeacije kroz kožu tijekom 48 h bio je $85,8 \%$, odnosno $0,0142 \mathrm{~cm} \mathrm{~h}^{-1}$ za formulaciju C3 (Eudragit RL 100 : Plasdone S 630; 4:6) i 88,0\%, odnosno 0,0155 $\mathrm{cm} \mathrm{h}^{-1}$ za formulaciju D3 (Eudragit RL 100 : PVP K 30; 4:6). FTIR i TLC ukazuju na to da nema interakcije između ljekovite tvari i polimera.

Ključne riječi: polimerni film, nitrendipin, transdermalni sustav za isporuku lijekova, Eudragit RL 100, Plasdone S 630, PVP K 30

ITS-Paramedical (Pharmacy) College, Ghaziabad, India

D. J. College of Pharmacy, Ghaziabad, India

Deparment of Pharmaceutics, Faculty of Pharmacy, Hamdard University, New Delhi, India 